\title{
COMPETÊNCIAS MATEMÁTICAS EM CRIANÇAS AUTISTAS: UM ESTUDO DE CASO
}

\section{MATHEMATICAL SKILLS IN AUTISTIC CHILDREN: A CASE STUDY}

\author{
Liliana Cristina Tavares, Isabel Calado \\ Instituto Politécnico de Coimbra \\ E-mail: Itavares@esec.pt, imcalado@hotmail.com

\section{António Pedro Costa} \\ Universidade de Aveiro \\ E-mail: pcosta@ludomedia.pt
}

\section{Estela Coelho}

Agrupamento de Escolas de Vale de Ovil - Baião, Portugal

E-mail: estelacoelho@gmail.com

\section{Resumo}

O artigo resume o estudo que analisou o "Dossier Pedagógico Barrinhas do Ludo, o Sonhador - Imagina, Constrói e Sonha com o Cuisenaire", identificando potencialidades e constrangimentos do seu uso com crianças autistas, em idade pré-escolar. Usou-se uma metodologia qualitativa, com enquadramento de estudo de caso, os dados foram recolhidos através da observação e analisados através da técnica de análise de conteúdo, identificando vantagens e desvantagens da utilização do material manipulável Cuisenaire com crianças autistas. Verificou-se que existem potencialidades associadas ao seu uso pelo que se desenvolveram competências no aluno: comunicativas, conhecimento dos atributos tamanho e cor, desenvolvimento da motricidade fina, entre outras.

Palavras-chave: Matemática. materiais manipuláveis estruturados. barras cuisenaire. Autismo. pré-escolar.

\section{Abstract}

This article summarizes the study and analysis of "Dossier Pedagógico Barrinhas do Ludo, o Sonhador - Imagina, Constrói e Sonha com o Cuisenaire", identifying potentials and constraints of their use with autistic children in preschool age. It was used a qualitative approach with case study framework, data were collected through observation and analyzed through content analysis technique, in order to be able to identify advantages and disadvantages of using Cuisenaire with children autistic. It was found that there are potential associated with their use for that developed skills in the student, such as: communication skills, knowledge of the size and color attributes, development of fine motor skills, among others.

Keywords: Math. manipulative structured materials. cuisenaire rods. autism. preschool. 


\section{INTRODUÇÃO}

O presente artigo apresenta a análise realizada ao "Dossier Pedagógico Barrinhas do Ludo, o Sonhador - Imagina, Constrói e Sonha com o Cuisenaire" (COSTA et al., 2009), de forma a identificar as potencialidades e constrangimentos na sua exploração com crianças autistas em contexto de educação pré-escolar, na ampliação de competências matemáticas, entre outras.

Decorrente da análise do Dossier Pedagógico, pretendeu-se verificar em que medida as competências definidas no mesmo foram desenvolvidas no aluno sob o qual incidiu o estudo. Para tal, aplicaram-se algumas das tarefas com o objetivo de promover a aquisição de novas competências no sujeito.

Precedido de um breve enquadramento teórico subordinado ao tema da educação préescolar e o domínio da matemática, apresenta-se inicialmente o material manipulável utilizado no estudo. Faz-se ainda referência à Perturbação Autística, contextualizando as principais características deste tipo de perturbação, de modo a compreender de que forma a utilização deste material poderá potencializar o seu utilizador. Finalmente, apresenta-se ainda a metodologia adotada para este estudo, bem como os resultados obtidos e as conclusões do trabalho.

\section{A EDUCAÇÃO PRÉ-ESCOLAR E O DOMÍNIO DA MATEMÁTICA}

A Lei-Quadro da Educação Pré-Escolar estabelece como princípio geral que:

\footnotetext{
A Educação Pré-Escolar é a primeira etapa da educação básica no processo de educação ao longo da vida sendo complementar da ação educativa da família, com a qual deve estabelecer estreita relação, favorecendo a formação e o desenvolvimento equilibrado da criança, tendo em vista a sua plena inserção na sociedade como ser autónomo, livre e solidário. (MINISTÉRIO DA EDUCAÇÃO, 1997, p.15)
} 
Por sua vez, as Orientações Curriculares para a Educação Pré-Escolar definidas pelo Ministério da Educação constituem-se como um instrumento de referência, um conjunto de princípios orientadores, para ajudar o Educador na tomada de decisões sobre a definição do processo educativo a desenvolver com as crianças, dando corpo à sua prática pedagógica. Atualmente surgem novos materiais e publicações, como as metas de aprendizagem e as brochuras para a Educação Pré-Escolar sobre o domínio da Matemática, que vêm aprofundar o primeiro documento orientador publicado, tendo como finalidade capacitar cada vez mais os Educadores para o correto desempenho da sua profissão, ambicionando-se ainda, que estas novas brochuras venham auxiliar o Educador no desenvolvimento e planificação de tarefas e atividades que levem os seus alunos a atingir no final da Educação Pré-Escolar, as competências definidas nas metas de aprendizagem para este ciclo de aprendizagens inicial.

As Orientações Curriculares para a Educação Pré-Escolar destacam ainda que:

Cabe ao Educador alargar intencionalmente as situações de comunicação, para diferentes contextos, com diversos interlocutores, conteúdos e intenções que permitam às crianças dominar progressivamente a comunicação como emissores e como recetores. (MINISTÉRIO DA EDUCAÇÃO, 1997, p.68).

Deste modo, o Educador tem um papel fundamental no processo comunicativo, nomeadamente na estruturação do discurso produzido em contexto escolar. O Educador é o grande impulsionador e promotor da comunicação, proporcionando momentos de discussão entre as crianças, levando a que estas explicitem os seus raciocínios com clareza, analisem e reajam aos raciocínios dos colegas.

Na Educação Pré-Escolar os conteúdos curriculares trabalhados organizam-se por áreas de conteúdo, a ramificação que se apresenta de seguida, pretende clarificar que todas as áreas de conteúdo devem ser consideradas aquando da execução de uma planificação de 
atividades a desenvolver em contexto de sala, com o grupo de crianças na valência de préescolar. Do mesmo modo, apresenta-se para que se possa perceber em qual das áreas de conteúdo se inscreve o domínio da Matemática.

Figura 1. Áreas de conteúdo da Educação Pré-Escolar.

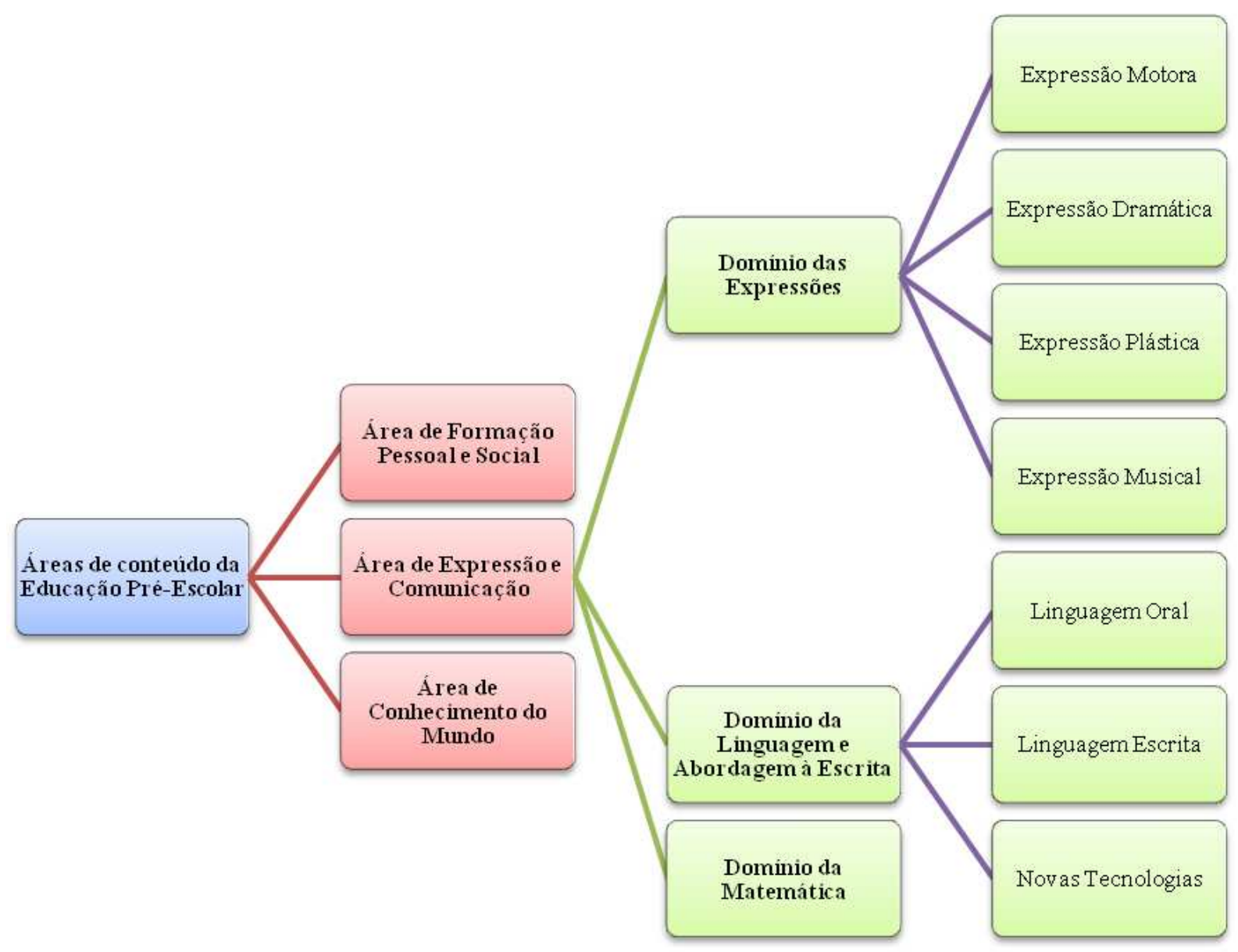

A disciplina de Matemática continua a ser uma das áreas académicas mais receadas pelos alunos, bem como pelos Educadores/Professores. A formação neste domínio revela-se de extrema importância, capacitando os profissionais da educação, para que desde cedo se sintam capazes de capacitar os seus alunos nesta área. Loureiro (2003) vem corroborar a ideia anterior referindo que uma das ideias dominantes é a da necessidade de proporcionar aos futuros Professores uma formação Matemática que os prepare para ensinar para a 
compreensão de ideias e conceitos matemáticos e para o desenvolvimento do raciocínio e da comunicação. Os primeiros anos da educação apresentam-se como sendo um tempo abençoado para as crianças, onde estas podem experimentar e sobretudo estabelecer relações sobre o que estão a experimentar. O Professor surge então como o elemento-chave da mudança, porque o seu papel é essencial para o ambiente que desencadeia no contexto de aprendizagem (SERRAZINA, 2001). A Matemática lida essencialmente com ideias, conceitos e resoluções de problemas. Neste contexto, o Educador deve criar um ambiente educativo que encoraje as crianças a explorar, testar, discutir e aplicar as suas ideias na resolução de problemas, enquanto construtoras do seu próprio conhecimento. As ideias matemáticas que as crianças exploram e adquirem nas primeiras idades são consideradas os alicerces para o desenvolvimento de aprendizagens futuras no âmbito da educação matemática. O Educador deverá estimular o seu grupo de crianças, capacitando-as para a resolução de problemas, dando-lhes o tempo necessário para que os possam explorar, resolver, comunicar formas de resolução e comparar as soluções encontradas, dotando-os de um raciocínio ávido, perspicaz e argumentativo.

As primeiras e verdadeiras experiências matemáticas acontecem no Jardim-de-Infância. É aí que, de diversas formas, as crianças experienciam situações matemáticas, essencialmente através do jogo e da exploração de materiais manipuláveis estruturados. Deste modo, a criança vai adquirindo competências em áreas extremamente diversificadas, salientando, neste contexto a Matemática, tornando os seus conteúdos mais atrativos e de abordagem mais realista. Ao ter em consideração as aprendizagens matemáticas, importa, mais do que o treino e prática desta ou daquela competência, que o jogo proposto envolva a criança em processos de análise; de raciocínio lógico; de descoberta de regras e padrões e de desenvolvimento de noções espaciais e geométricas. 


\section{OS MATERIAIS MANIPULATIVOS ESTRUTURADOS (MME)}

O recurso aos MME representa uma forma de promover o desenvolvimento e a aquisição de competências no domínio/área da Matemática. Os materiais manipuláveis são considerados, de certo modo, como um "estímulo para a aprendizagem da Matemática" (MINISTÉRIO DA EDUCAÇÃO, 1997), por isso há que proporcionar experiências de aprendizagem diversificadas e apoiar as crianças na construção e no desenvolvimento de conceitos no âmbito do domínio da Matemática. Damas et al. (2010), destacam os MME como "suportes de aprendizagem que permitem envolver os alunos numa construção sólida e gradual das bases Matemáticas.". As Orientações Curriculares para a Educação Pré-Escolar (MINISTÉRIO DA EDUCAÇÃO, 1997), à semelhança das referências anteriores destacam como materiais fundamentais, no âmbito de aprendizagens Matemáticas, a utilização do material Cuisenaire, dos Blocos Lógicos, Calculadores Multibásicos, Tangram e do Geoplano.

Figura 2. Os materiais manipuláveis estruturados (M.M.E).

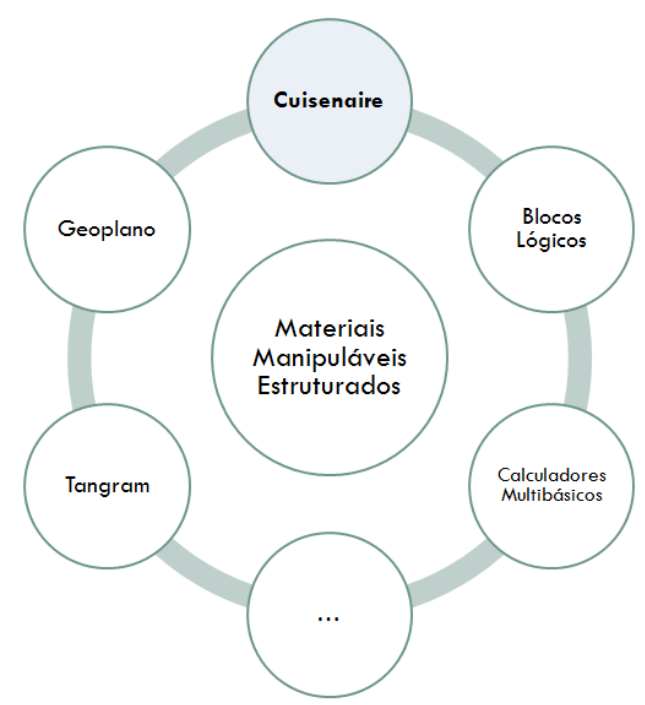

\subsection{O Material Manipulável Cuisenaire}

O Material Cuisenaire (Fig. 2), feito originalmente de madeira, é composto por um conjunto de barras com medidas de comprimento e cores diferentes, podendo simbolizar, cada barra, os números naturais até dez. A cada barra e consequentemente a cada medida de comprimento corresponde uma cor (COSTA et al., 2009, p.4). O material Cuisenaire foi 
projetado e criado por Georges Cuisenaire Hottelet (1891-1980), professor de ensino primário na aldeia belga de Thuin. Durante 23 anos, o material foi analisado e experimentado antes da sua publicação. $O$ professor belga concebeu este material a partir de réguas graduadas e caixas de aritmética com o objetivo de apoiar de forma estruturada a aprendizagem de conceitos básicos da Matemática.

Figura 3. Apresentação das Barras de Cuisenaire.

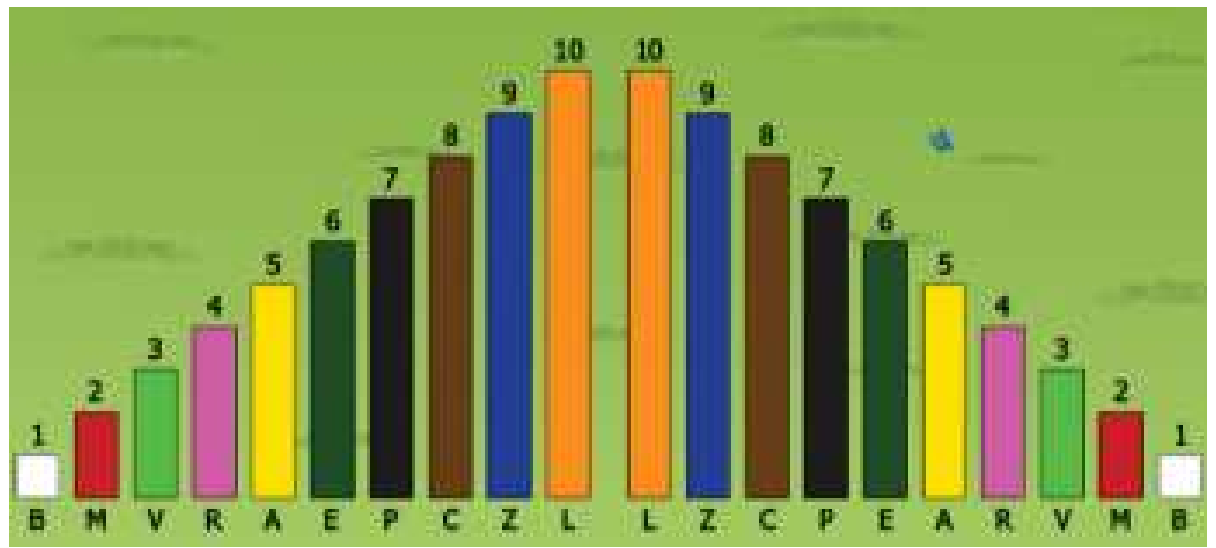

O material Cuisenaire começa a ser difundido, em 1952, pelo professor egípcio Caleb Gattegno com a publicação de "Les nombres en coleurs". Segundo Gattegno, este material surge como uma resposta à necessidade que sentia de ensinar a Matemática de uma forma lúdica e que, simultaneamente, permitisse aos alunos compreender e reter o que aprendiam sem recorrer exclusivamente a processos de memorização, mas principalmente pela vivência de experiências significativas conforme referenciam os autores Costa et al. (2009, p. 3). Estes definem ainda como uma grande vantagem da exploração do material Cuisenaire o facto de permitir à criança a criação e compreensão das estruturas matemáticas, em diferentes níveis de complexidade, de forma lúdica e, mais tarde, libertá-la da necessidade de recorrer a um suporte material para resolver problemas matemáticos. Na verdade, a manipulação e o trabalho com este material poderá permitir que a criança adquira um "saber fazer" muito antes de um saber teórico. Se o material for usado de forma apropriada, esse "saber fazer" poderá ser a primeira fase de um processo que conduzirá à abstração que engloba a fase de pesquisa empírica, a fase da sistematização e a fase do domínio das estruturas. 
Um trabalho de qualidade com as barras Cuisenaire permite desenvolver a atenção, a memória, a imaginação, a criatividade, as capacidades de cálculo mental, de associação, de comparação (igualdade, desigualdade e a relação de ordem), de dedução, a construção de noções matemáticas e a abstração. E, também, o sentido de número, incluindo a compreensão e utilização das relações entre as operações (adição, subtração, multiplicação e divisão). E, ainda, capacidades de observação, de motricidade fina e o sentido geométrico.

A utilização do material Cuisenaire permite, designadamente, fazer construções livres ou a partir de representações no plano; cobrir superfícies desenhadas em papel; ordenar números; compor e decompor números; explorar as propriedades das operações aritméticas elementares; explorar frações e decimais; construir gráficos de barras (colunas); explorar simetrias; explorar padrões; medir perímetros; medir áreas e volumes; comparar "partes de"; estabelecer relações de posição; construir itinerários; resolver problemas envolvendo os temas/tópicos referidos. (COSTA et al., 2009, p. 5).

\section{A PERTURBAÇÃO AUTÍ́STICA}

Segundo Oliveira (2010) "não é tarefa fácil definir o que é o autismo", no entanto e numa definição geral, pode dizer-se que esta é uma perturbação do desenvolvimento essencialmente caracterizada por grandes dificuldades na comunicação e no funcionamento social.

Na CID 10, o autismo faz parte do grupo de transtornos caracterizados por alterações qualitativas das interações sociais e modalidades de comunicação, e por um repertório de interesses e atividades restrito, estereotipado e repetitivo (que constituem uma característica global do funcionamento do sujeito, em todas as ocasiões), sendo caracterizado por um desenvolvimento anormal, que se manifesta antes dos três anos de idade, e apresentando uma perturbação do funcionamento em cada um dos três domínios 
seguintes: interações sociais, comunicação, e comportamento repetitivo. Além disso, o transtorno acompanha-se comummente de várias outras manifestações não específicas, como por exemplo, fobias, perturbações de sono ou da alimentação, crises de birra ou agressividade (autoagressividade).

O manual DSM-IV-TR (ASSOCIATION, 2006) refere o défice na comunicação como acentuado e persistente e que atinge tanto as aptidões verbais como as não-verbais. Pode produzir-se um atraso ou ausência total de desenvolvimento da linguagem oral, sendo que nos sujeitos que falam pode observar-se uma acentuada incapacidade na competência para iniciar ou manter uma conversação com os outros ou um uso estereotipado ou repetitivo da linguagem ou uma linguagem idiossincrática.

Os sujeitos com Perturbação Autística têm padrões de comportamento, interesses e atividades restritos, repetitivos e estereotipados. Revelam uma acentuada restrição na variedade de interesses e preocupação com um único interesse muito limitado (por exemplo, interessados apenas em datas, números de telefone e nomes de emissoras radiofónicas). Podem alinhar um número exato de peças de jogo sempre e da mesma maneira ou reproduzir repetidamente comportamentos de um ator da televisão.

Há frequentemente um interesse por rotinas ou rituais não funcionais ou uma insistência irracional em seguir determinadas rotinas (por exemplo, seguir todos os dias exatamente o mesmo percurso para ir à escola). Os movimentos corporais estereotipados incluem os que são feitos com as mãos (bater palmas, estalar os dedos) ou todo o corpo (balançar-se, inclinar-se, mexer-se). Podem estar presentes anomalias posturais (por exemplo, andar na ponta dos pés, movimentos estranhos das mãos e posturas corporais estranhas). Estes sujeitos revelam uma preocupação persistente por certas partes dos objetos ou por movimentos.

A perturbação pode manifestar-se antes dos 3 anos de idade por um atraso ou 
funcionamento anormal em pelo menos uma das seguintes áreas: interação social, linguagem usada na comunicação social, jogo simbólico ou imaginativo.

\section{PERCURSO METODOLÓGICO}

A conceptualização da investigação para este estudo em particular, consiste na implementação de um leque de tarefas do recurso "Barrinhas do Ludo, o Sonhador Imagina, Constrói e Sonha com o Cuisenaire", a uma criança portadora do espectro do autismo, pretendendo-se aferir quais as tarefas deste recurso passíveis de serem aplicadas em crianças autistas, analisando-se ainda se o aluno adquiriu novas competências promovidas pela sua exploração.

Importa, antes de mais, caracterizar o aluno sob o qual incidiu este estudo de caso. No início da intervenção o F. tinha sido observado/avaliado na Consulta de Autismo a 6 de Setembro de 2012, a pedido do Dr. Manuel Baptista Salgado (Médico Pediatra), por suspeita de perturbação do espectro do autismo. Frequentou o jardim de infância desde os dois anos e beneficia de Terapia da Fala. Foi referenciado por apresentar atraso de linguagem associado a dificuldades de interação social e brincadeiras estereotipadas. Em consulta mantinha interação pobre, caracteristicamente instrumental. Interesse consistentemente direcionado para os objetos em detrimento das pessoas. Jogo simbólico pobre. Birras frequentes. A observação/avaliação realizada em contexto de consulta permitiu confirmar o diagnóstico Perturbação do Espetro do Autismo. Passou a frequentar o Externato "O Despertar" em Maio de 2013 e a intervenção realizada com este recurso implementou-se a partir de Setembro de 2015. 
Figura 4. Apresentação do recurso "Barrinhas do Ludo, o Sonhador - Imagina, Constrói e Sonha com o Cuisenaire".

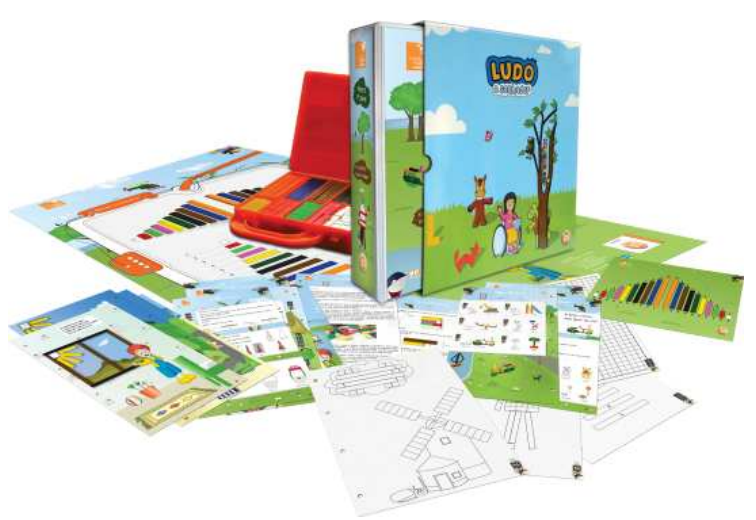

O recurso contém um manual pedagógico, constituído por dois separadores: um com a história "A Ilha AEIOU" e respetivas tarefas para o aluno e ainda outro separador intitulado "Oficina Pirimpar" com propostas de tarefas que compreendem a utilização das barras cuisenaire. Contém ainda um poster, um mural, um tabuleiro quadriculado e um tabuleiro de associação tamanho/código. O separador "A Ilha AEIOU" apresenta as seguintes finalidades, decorrentes da exploração do recurso a desenvolver no aluno: desenvolver a motricidade fina, desenvolver competências comunicativas, desenvolver a capacidade de trabalho em grupo, conhecer o atributo código correspondente às barras, ordenar objetos segundo as medidas de comprimento, continuar e criar padrões, completar uma figura de forma a que apresente simetria de reflexão, determinar a imagem de uma figura dada por reflexão, ampliar uma construção, respeitando as regras dadas, conhecer o atributo tamanho e conhecer o atributo cor.

Por sua vez, o separador "Oficina Pirimpar" propõe também o desenvolvimento das seguintes finalidades, decorrentes da exploração do recurso: desenvolver a motricidade fina, desenvolver competências comunicativas, desenvolver a capacidade de trabalho em grupo, conhecer os atributos tamanho e cor, gerar sequências, estabelecer relações de grandeza e de posição entre objetos, ordenar objetos segundo as medidas de comprimento, interpretar códigos, completar e interpretar tabelas, comparar objetos segundo os conceitos de número 
par e ímpar, identificar objetos segundo um critério, quantificar agrupamentos, efetuar contagens, ler e escrever números, identificar sequências e reproduzi-las usando outras representações, reproduzir itinerários, desenvolver a lateralidade e por último, fazer composições.

Tendo como base o recurso apresentado definiram-se como específicos deste trabalho de investigação os seguintes objetivos: i) aferir qual a perceção da criança no que concerne à ilustração das histórias do recurso, atendendo às construções apresentadas no contexto ilustrativo; ii) compreender se o aluno é capaz de replicar figuras que observa nos tabuleiros disponibilizados; verificar em que medida a criança identifica as cores das barras e é capaz de as verbalizar; iii) testar em que medida a criança compreende a diferença de tamanho das barras, atribuindo-Ihes uma organização específica; iv) aferir se a criança compreende ordens de grandeza numéricas associadas ao material manipulável; identificar quais as tarefas que o aluno é capaz de completar, e; v) verificar quais as competências desenvolvidas no aluno com a utilização regular deste material manipulável, comparando-as com as finalidades acima descritas.

Deste modo, pretendeu-se verificar através da observação (participante), diversos registos, de modo a verificar se as atividades do recurso implementadas permitiram desenvolver no aluno novas competências.

Depois de recolhidos os dados, procedeu-se ao seu tratamento através do software de análise de dados webQDA (SOUSA; COSTA e MOREIRA, 2001), utilizado no apoio à análise de dados qualitativos num ambiente colaborativo e distribuído.

A análise das imagens e dos vídeos foi efetuada através da criação de segmentos/rótulos. Cada segmento e rótulo foi precedido de uma descrição factual e/ou interpretativa. Alguns vídeos permitiram transcrever algumas falas do aluno. 


\section{RESULTADOS E DISCUSSÃO}

Neste ponto apresenta-se a análise dos dados recolhidos, através de gráficos que permitem compreender se as tarefas exploradas do recurso “Dossier Pedagógico Barrinhas do Ludo, o Sonhador - Imagina, Constrói e Sonha com o Cuisenaire", são ou não pertinentes na estimulação de competências matemáticas em crianças autistas.

Deste modo, os resultados obtidos permitem inferir, de um modo global, quais as competências trabalhadas em cada separador do recurso, bem como as respetivas percentagens, relativamente ao número total de referências registadas aquando da implementação das atividades. O número de referências registadas diz respeito ao número de vezes em que se assinalou/codificou a imagem ou vídeo para o desenvolvimento de determinada competência.

Figura 5. Finalidades do Separador - "A Ilha AEIOU".

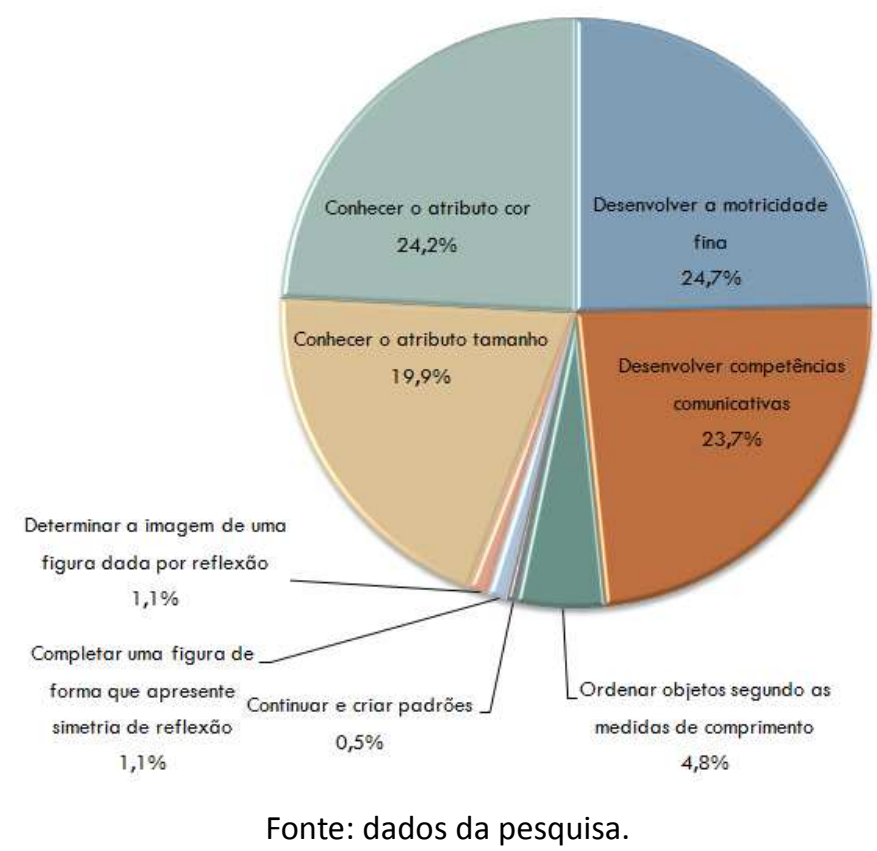


Figura 6. Finalidades do Separador - "Oficina Pirimpar".

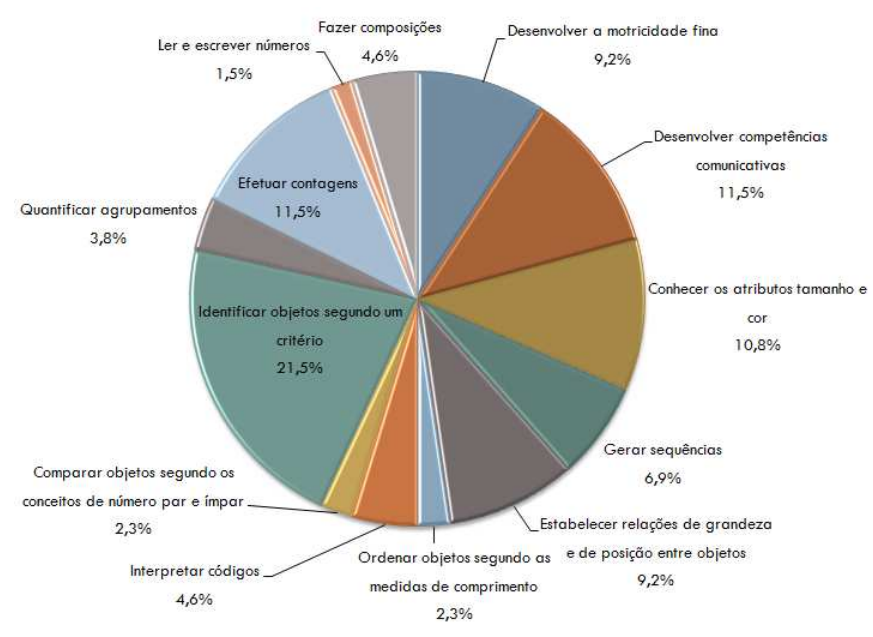

Fonte: dados da pesquisa.

De acordo com os gráficos apresentados anteriormente, é possível verificar que no separador "A Ilha AEIOU", numa análise mais pormenorizada das finalidades do mesmo, existem 4 finalidades enunciadas no recurso que se destacam das restantes, por apresentarem percentagens de referenciação mais elevadas comparativamente às restantes finalidades listadas, sendo estas: "Desenvolver a motricidade fina" (24,7\%), "Desenvolver competências comunicativas" (23,7\%), "Conhecer o atributo tamanho" $(19,9 \%)$ e "Conhecer o atributo cor" $(24,2 \%)$, sendo que a soma destas finalidades representa $92,5 \%$ do total de referências (11) registadas para este separador. O facto de estas percentagens serem elevadas relativamente às restantes finalidades listadas, permite afirmar que as mesmas foram efetivamente trabalhadas com o aluno na implementação das atividades, ou seja, permite concluir que, de facto, o aluno desenvolveu estas competências.

No que se refere ao segundo separador, esta evidência já não é tão clara, uma vez que as percentagens de referenciação respeitantes às finalidades listadas no mesmo não são tão elevadas, mas permite concluir, no entanto, que existem finalidades elencadas que foram referenciadas de forma equitativa relativamente a todas as outras, nomeadamente: "Desenvolver a motricidade fina" (9,2\%), "Desenvolver competências comunicativas" (11,5\%), "Conhecer os atributos tamanho e cor" (10,8\%), "Estabelecer relações de grandeza e 
de posição entre objetos" (9,2\%) e "Efetuar contagens" (11,5\%). Por outro lado, destaca-se, por apresentar a maior percentagem do total de referências listadas (21,5\%), a finalidade "Identificar objetos segundo um critério", que permite afirmar que esta finalidade foi efetivamente trabalhada com o aluno durante a implementação das atividades e que o mesmo desenvolveu, de forma mais efetiva, esta competência. A soma das percentagens das 5 finalidades referidas anteriormente representa $73,8 \%$ do total de referências (18) registadas para este separador e, portanto, a maioria das referências registadas no mesmo.

No geral, existem 4 finalidades que se podem destacar de todas as restantes, independentemente do número de atividades trabalhadas em cada separador, por serem comuns a ambos (Desenvolver a motricidade fina, Desenvolver competências comunicativas, Conhecer os atributos tamanho e cor e Ordenar objetos segundo as medidas de comprimento). A indicação das respetivas referências, registadas em ambos os separadores, bem como a soma das mesmas, apresenta-se abaixo:

Figura 7. Finalidades comuns a ambos os separadores.
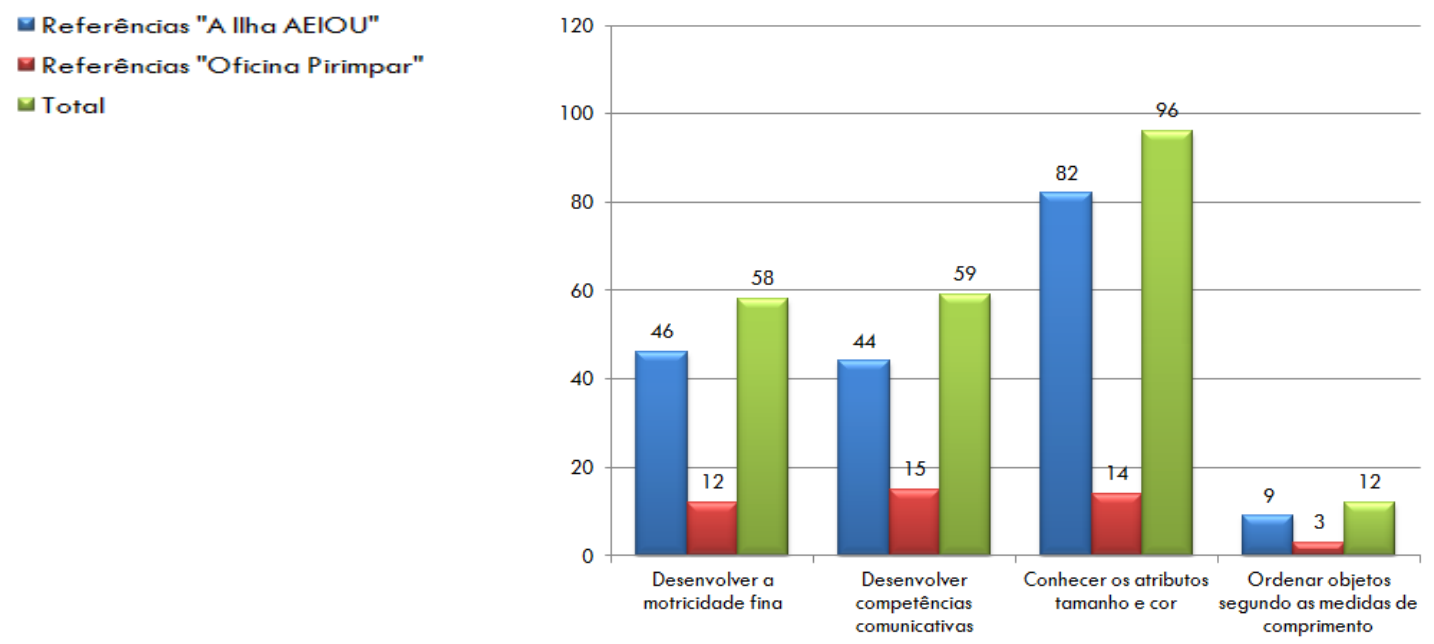

Fonte: dados da pesquisa.

A análise da figura anterior permite concluir, através da comparação das finalidades apresentadas, que a que mais se destaca, por ter uma maior percentagem de referenciação relativamente ao total de referências registadas, é a finalidade "Conhecer os atributos 
tamanho e cor", representando esta $43 \%$ da totalidade de referenciações realizadas. De seguida, com $26 \%$ do total de referências, surge a finalidade "Desenvolver a motricidade fina" e "Desenvolver competências comunicativas". Finalmente, verifica-se que a finalidade "Ordenar objetos segundo as medidas de comprimento", com 5\% do total de referências, se confirma como a menos relevante das 4 finalidades apresentadas, pois esta representava apenas 4,8\% das referências no separador "A Ilha AEIOU" e 2,3\% no separador "Oficina Pirimpar".

Finalmente, da análise do gráfico anterior verifica-se que as finalidades "Desenvolver a motricidade fina" e "Desenvolver competências comunicativas", para além de terem a mesma percentagem de referências (26\%), representam, em cada separador, a mesma importância no que se refere ao facto do aluno ter desenvolvido estas mesmas competências, por apresentarem percentagens de referenciação muito semelhantes. No separador "A Ilha AEIOU", as referidas finalidades representam 24,7\% e 23,7\%, respetivamente, relativamente ao total de referências registadas e no separador "Oficina Pirimpar", 9,2\% e 11,5\%, respetivamente.

Desta análise verifica-se que existem várias competências em ambos os separadores que não foram trabalhadas e referenciadas durante a implementação das atividades, bem como outras que não foram referenciadas com a frequência espectável. Tal situação deve-se ao facto de que o aluno não se demonstrou motivado para executar atividades que promovessem o desenvolvimento das finalidades que não obtiveram referências no sistema de codificação. Contudo, a quantidade de dados recolhidos permitiu obter dados suficientes que permitiram concluir que a aplicação de tarefas do recurso com esta criança portadora do espectro do autismo é pertinente na estimulação de competências matemáticas. 


\section{CONSIDERAÇÕES FINAIS}

O trabalho realizado permitiu analisar o recurso "Dossier Pedagógico Barrinhas do Ludo, o Sonhador - Imagina, Constrói e Sonha com o Cuisenaire", atribuindo-Ihe, para o efeito, as potencialidades da sua utilização, bem como os constrangimentos a ele associados neste público-alvo.

Importa ainda referir que este trabalho de investigação foi direcionado para um estudo de caso e que os resultados alcançados permitem ter uma ideia de aplicabilidade prática para com outras crianças, mas poderão não ser conclusivos em relação aos benefícios, visto existirem diferentes realidades, dentro do espectro do autismo.

Seria deveras interessante e relevante num futuro estudo, poder aplicar o mesmo leque de atividades com um público-alvo mais extenso, de modo a tentar compreender de que forma este recurso poderá ser efetivamente potenciador de novas aprendizagens.

Neste estudo, teria sido pertinente proceder à aplicação das tarefas do recurso por um período mais alargado de tempo, de modo a abranger todas as atividades propostas, tentando compreender, deste modo, quais as variáveis que influenciariam a recolha dos resultados. Para este facto contribuíram, para além do referido anteriormente, o tempo disponível para trabalhar com o aluno face ao restante grupo heterogéneo; a alteração e reajustamento de medicação no aluno, que comprometeu a sua estabilidade em contexto de sala de aula; as reuniões de articulação com os restantes técnicos (educadora da intervenção precoce, terapeuta da fala, terapeuta ocupacional) para o reajustamento e a avaliação do Plano Individual de Intervenção Precoce (PIIP), bem como a frequência do aluno nas terapias assinaladas.

Futuramente desejar-se-ia, para além de alargar a implementação do estudo a um público mais alargado de crianças, tornar este recurso interativo, adaptando as tarefas do "Dossier 
Pedagógico Barrinhas do Ludo, o Sonhador - Imagina, Constrói e Sonha com o Cuisenaire", para suporte digital, através do desenvolvimento de aplicações para equipamentos móveis, tais como tablets ou smartphones.

Schlunzen (2005), afirma que as tecnologias podem constituir um recurso fundamental para possibilitar a comunicação das pessoas com necessidades educativas especiais, permitindo uma manipulação do meio e um melhor desenvolvimento cognitivo. Por sua vez, Barbosa (2009), evidencia que a aprendizagem de pessoas com autismo com recurso a novas tecnologias e explorando a apresentação visual dos meios multimédia recentes, vai ao encontro à afirmação do autor, que relata que as pessoas com perturbações do espectro do autismo aprendem melhor quando a informação é apresentada de forma visual.

As tarefas implementadas dos dois separadores do recurso permite afirmar que a exploração do mesmo possibilitou a ampliação da comunicação verbal do aluno que era francamente deficitária.

Por sua vez, através da análise efetuada aos dados recolhidos, é possível verificar que o aluno compreendeu a escala numérica associada ao material, sendo também capaz de reconhecer as cores e os tamanhos associados às barras. Do mesmo modo, revela-se capaz de sobrepor as barras nos tabuleiros disponibilizados, identificando a maioria das figuras a que correspondem e atribuindo-Ihes um significado válido.

\section{AGRADECIMENTOS}

O presente trabalho não teria sido possível sem a colaboração de outras pessoas, por isso, gostaria de manifestar a minha gratidão a todos aqueles que contribuíram direta ou indiretamente para a sua concretização. Um agradecimento especial à orientadora deste projeto, pelo apoio e disponibilidade, bem como ao coorientador pelo incentivo e motivação constante. 


\section{REFERÊNCIAS}

ASSOCIATION, Manual de Diagnóstico e Estatística das Perturbações Mentais, Lisboa: Climepsi Editores, 2006.

BARBOSA, H. "Análise do recurso a novas tecnologias no ensino de autistas", Instituto Superior de Engenharia do Porto: Porto, 2009.

COSTA, António P. et al. Dossier Pedagógico Barrinhas do Ludo, o sonhador: Imagina, Constrói e Sonha com o Cuisenaire. Oliveira de Azeméis: Ludomedia - Conteúdos Didáticos e Lúdicos, 2009.

DAMAS, Ermelinda et al. Alicerces da Matemática - Guia Prático para Educadores e Professores, Porto: Areal Editores, S.A., 2010.

LOUREIRO, Cristina. "Que formação matemática para os professores do 10 ciclo e para os educadores de infância?” em A Matemática na Formação do Professor. Sociedade Portuguesa de Investigação em Educação Matemática: Évora, 2003.

MINISTÉRIO DA EDUCAÇÃO, d. E. B. "Orientações Curriculares para a Educação Pré-Escolar", Lisboa: Editorial do Ministério da Educação, 1997.

OLIVEIRA, Tânia. "A intervenção precoce no Autismo e Trissomia 21: Orientações para boas práticas de intervenção", Universidade de Coimbra - Faculdade de Psicologia e de Ciências da Educação, 2010.

SCHLUNZEN, M. "A tecnologia para inclusão de pessoas com necessidades especiais", Rio de Janeiro: DP\&A, 2005.

SERRAZINA, Lurdes. "A formação para o ensino da matemática na educação: perspectivas futuras" Revista Portuguesa de Formação de Professores, pp. 77-85, 2001.

SOUZA, Francislê N. et al, "webQDA", Aveiro: Centro de Investigação Didática e Tecnologia na Formação de Formadores da Universidade de Aveiro e Esfera Crítica, 2001. 